\title{
Urinary levels of early kidney injury molecules in children with vitamin B12 deficiency
}

\author{
Ali Güneş, M.D. ${ }^{a}$, Fesih Aktar, M.D. ${ }^{a}$, Ilhan Tan, M.D. ${ }^{a}$, Murat Söker, M.D. ${ }^{b}$, Ünal Uluca, M.D..$^{a}$ \\ Hasan Balık, M.D. ${ }^{a}$ and Nuriye Mete, M.D. ${ }^{c}$ \\ Collaborator: Velat Şen, M.D. ${ }^{a}$
}

\begin{abstract}
The aim of this study was to investigate urine early kidney injury molecules, including human kidney injury molecule-1 (KIM-1), liver-type fatty-acid binding protein (L-FABP), $\mathrm{N}$-acetyl-b-D-glucosaminidase A (NAG), and neutrophil gelatinase-associated lipocalin (NGAL) in children with vitamin B12 (cobalamin) deficiency (CD). Twelve children with vitamin B12 deficiency and 20 healthy matched controls were included. Hematologic parameters, serum urea, creatinine $(\mathrm{Cr})$, electrolytes, B12 and folate levels were recorded. Estimated glomerular filtration rate (eGFR) was calculated. Urine protein, electrolytes, and urinary early markers were measured. Patients with $C D$ had significantly higher urine electrolyte/Cr ratios ( $p<0.05$ ). Significantly higher urinary KIM-1/Cr, L-FABP/Cr, $\mathrm{NAG} / \mathrm{Cr}$ and NGAL/Cr were found in CD group $(\mathrm{p}<0.05)$. Significant negative correlations were found between levels of serum B12 and urinary markers in the patients $(\mathrm{p}<0.05)$. Increased urinary kidney injury molecules and electrolytes in children with B12 deficiency suggest a possible subclinical renal dysfunction, which cannot be determined by conventional kidney function tests.

Key words: vitamin B12 deficiency, kidney injury, KIM-1, L-FABP, NAG, NGAL.

http:/ /dx.doi.org/10.5546/aap.2016.eng.453
\end{abstract}

\section{INTRODUCTION}

Vitamin B12 (cobalamin) is an essential ingredient for cell growth and proliferation, hematopoiesis, and neurological functions. ${ }^{1}$ Cobalamin deficiency (CD) is a worldwide problem in all age groups. Cobalamin deficiency

a. Dicle University, Medical School Department of Pediatrics, Diyarbakir, Turkey.

b. Dicle University, Medical School Department of Pediatric Hematology, Diyarbakir, Turkey.

c. Dicle University, Medical School Department of Biochemistry, Diyarbakir, Turkey.

E-mail address: Ali Güneş, M.D.: draligunes@gmail.com

Funding: None.

Conflict of interest: None.

Received: 2-2-2016

Accepted: 5-6-2016 may result in a variety of symptoms, since vitamin B12 is essential for nucleic acid synthesis, erythrocytes and for the maintenance of myelin. ${ }^{2}$ Neurological symptoms such as hypotonia, seizures and developmental delay can be seen in infants, while in older children megaloblastic hematological changings, extrapyramidal signs and delirium or psychosis can be observed. ${ }^{3}$ Selective vitamin B12 malabsorption or GräsbeckImerslund syndrome has been reported together with proteinuria ${ }^{4}$. In addition, if CD advances, it will cause anemia, ${ }^{2}$ which may lead to chronic hypoxia as one of the causes of kidney injury. ${ }^{5}$ Although hematological and neurological aspects of $C D$ have been investigated extensively, there is no study on renal effects of CD in the literature search.

Serum levels of blood urea nitrogen or creatinine do not increase until more than half of the kidney functions are lost. ${ }^{6}$ Therefore, noninvasive early biomarkers that predict subclinical renal damage are necessary. The most promising biomarkers are human kidney injury molecule-1 (KIM-1), liver-type fatty-acid binding protein (L-FABP), N-acetyl-b-D-glucosaminidase A (NAG), and neutrophil gelatinase-associated lipocalin (NGAL). In this study, we used new injury markers including KIM-1, L-FABP, NAG and NGAL to investigate the possible subclinical effects of $C D$ on kidney functions.

According to our search in English literature, we could not find any study investigating early markers of kidney damage in children with B12 deficiency. Thus, in this study, we aimed to investigate the possibility of subclinical renal injury, which cannot be determined through conventional methods in children with CD.

\section{MATERIALS AND METHODS}

Twelve children (7 male, 5 female) with CD, who admitted to the Dicle University Hospital between April and December 2015 period were included. The control group consisted of age- and gender-matched 20 healthy children (11 male, 9 female), who were admitted to the hospital due to a routine check-up or minor surgery, without 
anemia or any disease/drug use affecting the kidney functions. Medical history, complaints, and physical examination findings were recorded. Children with diabetes mellitus, rheumatic disease, urinary tract infection, sepsis, kidney disease, history of nephrotoxic drug use, or liver, heart or respiratory disease were excluded.

Blood hemoglobin $(\mathrm{Hb})$, white blood cell count (WBC), red blood cells (RBC), mean corpuscular volume (MCV), mean corpuscular hemoglobin concentration (MCHC), and platelet count (PLT) were recorded. Anemia in childhood was defined as a hemoglobin $(\mathrm{Hb})$ concentration below cut off levels established by the World Health Organization: $11 \mathrm{~g} / \mathrm{dl}$ in children aged 6-59 months, $11.5 \mathrm{~g} / \mathrm{dl}$ in children aged 5-11 years and $12 \mathrm{~g} / \mathrm{dl}$ in children $12-$ 14 years old. ${ }^{7}$ Biochemical analyses included, serum urea, creatinine $(\mathrm{Cr})$, electrolytes [sodium $(\mathrm{Na})$, potassium $(\mathrm{K})$, calcium $(\mathrm{Ca})]$, aspartate transaminase (AST), alanin aminotransferase (ALT), lactate dehydrogenase (LDH), C-reactive protein (CRP), and B12 vitamin and folate levels. Diagnosis of $C D$ was done when vitamin B12 levels were $<148 \mathrm{pmol} / \mathrm{L}$, with normal folate levels, and with exclusion of other causes of anemia. ${ }^{2}$

Urine samples of $10 \mathrm{ml}$ were centrifuged for 3 minutes at $3000 \mathrm{rpm}$ and urine at upper part of the tube was filled in four separate Eppendorf tubes and stored at $-80{ }^{\circ} \mathrm{C}$ until measurements.
The following variables were studied in the urine samples: $\mathrm{Ca}, \mathrm{Na}, \mathrm{K}$, magnesium $(\mathrm{Mg})$, uric acid (UA), protein, and $\mathrm{Cr}$. Urinary early markers of kidney injury including KIM-1, L-FABP, NAG and NGAL were also measured. Biochemical parameters were investigated by an Abbott ARCHITECT C16000 (Abbott Park, IL) device through an enzymatic colorimetric method. Early markers of kidney damage were examined by enzyme linked immunosorbent assay (ELISA) method. Urine electrolyte and early renal injury markers' concentrations were divided by the urine creatinine for comparisons. The eGFR was estimated from serum creatinine by using bedside Schwartz formula for children. ${ }^{8}$

The study complied with the Declaration of Helsinki, all subjects gave informed consent and the study protocol was approved by the Ethics Committee of the Dicle University Medical School.

Numerical data were presented as mean plus/minus standard deviation, median, and maximum-minimum; whereas categorical data were given as a number and percentage. MannWhitney U-test was used for comparison between independent groups. Chi-square test was used to compare the categorical data. Relationships between data were investigated by using Spearman's correlation analyses. P value of less than 0.05 was considered statistically significant.

TABLE 1. Demographic and biochemical characteristics of cobalamin (B12) deficiency and the control group [Median (minimum-maximum)]

\begin{tabular}{lccc}
\hline & B12 Deficiency group $(\mathbf{n = 1 2})$ & Control group $(\mathbf{n = 2 0})$ & $p$ \\
\hline Age $($ years $)$ & $8.0(1.0-14.0)$ & $5.0(2.0-11.0)$ & NS \\
Height $(\mathrm{cm})$ & $125.0(74.0-157.0)$ & $109.0(75.0-145.0)$ & NS \\
eGFR $\left(\mathrm{ml} / \mathrm{min} / 1.73 \mathrm{~m}^{2}\right)$ & $101.7(90.6-115.8$ & $104.7(83.4-121.5)$ & NS \\
Serum vitamin B12 $(\mathrm{pg} / \mathrm{ml})$ & $111.0(50.0-147.0)$ & $298.0(122-442.0)$ & $<0.001$ \\
Serum folate $(\mathrm{ng} / \mathrm{ml})$ & $17.5(9.2-23.0)$ & $15.0(11.0-19.0)$ & NS \\
Serum glucose $(\mathrm{mg} / \mathrm{dl})$ & $92.0(84.0-124.0$ & $87.0(79.0-100.0)$ & NS \\
Serum urea $(\mathrm{mg} / \mathrm{dl})$ & $17.0(15.0-223.0)$ & $18.0(15.0-23.0)$ & NS \\
Serum creatinine $(\mathrm{mg} / \mathrm{dl})$ & $0.50(0.31-0.56)$ & $0.49(0.33-0.58)$ & NS \\
Serum sodium $(\mathrm{mEq} / \mathrm{L})$ & $(136.0(134.0-139.0)$ & $137.0(131.0-141.0)$ & NS \\
Serum potassium $(\mathrm{mEq} / \mathrm{L})$ & $4.5(3.1-5.3)$ & $4.3(3.8-5.9)$ & NS \\
Serum calcium $(\mathrm{mg} / \mathrm{dl})$ & $10 .(7.8-10.4)$ & $9.7(9.0-11.0)$ & NS \\
Serum AST $(\mathrm{IU} / \mathrm{L})$ & $34.0(15.0-42.0)$ & $26.5(14.0-48.0)$ & $\mathrm{NS}$ \\
Serum ALT $(\mathrm{IU} / \mathrm{L})$ & $20.0(9.0-43.0)$ & $15.0(8.0-35.0)$ & $\mathrm{NS}$ \\
Serum LDH $(\mathrm{IU} / \mathrm{L})$ & $345.0(223.0-2313.0)$ & $254.5(169.0-330.0)$ & $<0.001$ \\
\hline
\end{tabular}

eGFR: Estimated glomerular filtration rate;AST:Aspartat transaminase;ALT: Alanin aminotransferase; LDH: Lactate dehydrogenase; NS: Not significant. 


\section{RESULTS}

Twelve (7 male, 5 female) children with CD were included. The control group consisted of 20 (11male, 9 female) healthy children. There was no significant difference in the mean age of children with $\mathrm{CD}$ and the healthy controls $(6.9 \pm 4.6$ vs. $5.3 \pm 2.4$ years $)(p>0.05)$ (Table 1$)$.

No significant differences were found in eGFR, and serum urea, $\mathrm{Cr}, \mathrm{Na}, \mathrm{K}, \mathrm{Ca}, \mathrm{ALT}, \mathrm{AST}$, glucose, and folate levels between $\mathrm{CD}$ patients and the control subjects. The mean serum vitamin B12 level was significantly lower in the $C D$ group compared to the controls ( $p<0.001$ ); however, serum LDH level was significantly higher in CD group ( $\mathrm{p}<0.001)$ (Table 1$)$.

Significantly lower values of $\mathrm{RBC}, \mathrm{Hb}, \mathrm{Hct}$ $(\mathrm{p}<0.001)$ and higher levels of MCV and MCHC were found in CD group ( $p<0.001 ; p=0.035$, for each). There were no significant differences in WBC and PLT counts between two groups $(\mathrm{p}>0.05)$ (Table 2).

Children with $\mathrm{CD}$ had significantly higher urine $\mathrm{KIM}-1 / \mathrm{Cr}$, NGAL/Cr, NAG/Cr and $\mathrm{L}-\mathrm{FABP} / \mathrm{Cr}$ ratios compared with the healthy controls $(\mathrm{p}=0.008 ; \mathrm{p}=0.019 ; \mathrm{p}=0.003 ; \mathrm{p}=0.011$; respectively) (Table 3 ).

Although CD patients had significantly higher urine $\mathrm{Na} / \mathrm{Cr}$, and $\mathrm{UA} / \mathrm{Cr}$ values compared to the control group ( $p=0.029 ; p=0.025$, respectively), no significant differences were found in urine $\mathrm{P} / \mathrm{Cr}, \mathrm{Mg} / \mathrm{Cr}, \mathrm{K} / \mathrm{Cr}, \mathrm{Ca} / \mathrm{Cr}$ and Protein $/ \mathrm{Cr}$ values between the two groups (Table 4).

TABLE 2. Hematological characteristics of cobalamin deficiency and the controls groups [Median (minimum-maximum)]

\begin{tabular}{lccc}
\hline & B12 Deficiency group $(\mathbf{n = 1 2})$ & Control group $(\mathbf{n}=\mathbf{2 0})$ & $p$ \\
\hline WBC & $9.1(8.8-14.4)$ & $8.0(5.4-10.4)$ & NS \\
RBC $\left(\times 10^{6}\right.$ cells/ $/ \mathrm{L}$ & $3.7(1.3-4.2)$ & $4.8(4.2-6.6)$ & $<0.001$ \\
Hemoglobin $(\mathrm{g} / 100 \mathrm{~mL})$ & $10.1(4.4-11.2)$ & $13.0(12.0-15.0)$ & $<0.001$ \\
Hematocrit $(\%)$ & $30.4(12.6-33.6)$ & $39.0(32-49.0)$ & $<0.001$ \\
MCV $(\mathrm{fL})$ & $90.0(82.3-96.0)$ & $80.1(73.4-87.0)$ & $<0.001$ \\
MCHC $(\mathrm{g} / \mathrm{dL})$ & $34.3(32.1-36.9)$ & $32.4(27.0-35.0)$ & 0.031 \\
PLT count $\left(\times 10^{3} / \mathrm{mm}^{3}\right)$ & $273.0(127.0-664.0)$ & $288.5(304.6-664.0)$ & $\mathrm{NS}$ \\
\hline
\end{tabular}

WBC: Whiteblood cells; RBC: Red blood cells; MCV:Mean corpuscular volume, MCHC: Mean corpuscular hemoglobin concentration; PLT: Platelets; NS: Not significant.

TABLE 3. Urinary levels of early kidney injury molecule cobalamin deficiency and the control groups [Median (minimummaximum)]

\begin{tabular}{lccc}
\hline & B12 Deficiency group $(\mathbf{n}=\mathbf{1 2})$ & Control group $(\mathbf{n}=\mathbf{2 0})$ & $p$ \\
\hline KIM-1/Cr & $0.08(0.01-0.32)$ & $0.01(0.00-0.03)$ & 0.008 \\
NGAL/Cr & $19.5(3.1-87.1)$ & $3.9(1.1-10.5)$ & 0.019 \\
NAG/Cr & $0.81(0.13-5.85)$ & $0.19(0.04-0.70)$ & 0.003 \\
L-FABP/Cr & $3.87(0.76-19.21)$ & $0.90(0.34-2.09)$ & 0.011 \\
\hline
\end{tabular}

NGAL: Neutrophil gelatinase-associated lipocaline; NAG: N-acetyl-b- D -glucosaminidase; L-FABP: Liver-type fatty acid-binding protein;KIM-1: Human Kidney injury molecule-1; Cr: Creatinine.

TABLE 4. Urinary electrolytes to creatinine ratios in the cobalamin deficiency and control group [Median (minimummaximum)]

\begin{tabular}{|c|c|c|c|}
\hline & B12 Deficiency group $(n=12)$ & Control group $(n=20)$ & $p$ \\
\hline $\mathrm{Na} / \mathrm{Cr}$ & $2.27(1.21-14.25)$ & $1.74(0.40-5.37)$ & 0.029 \\
\hline $\mathrm{K} / \mathrm{Cr}$ & $0.76(0.39-2.33)$ & $0.56(0.19-2.25)$ & NS \\
\hline $\mathrm{Ca} / \mathrm{Cr}$ & $0.12(0.02-1.30)$ & $0.05(0.01-0.26$ & NS \\
\hline $\mathrm{P} / \mathrm{Cr}$ & $0.52(0.15-2.02)$ & $0.65(0.23-1.22)$ & NS \\
\hline $\mathrm{Mg} / \mathrm{Cr}$ & $0.17(0.05-0.25)$ & $0.09(0.03-0.25)$ & NS \\
\hline Protein/Cr & $0.09(0.05-0.26)$ & $0.09(0.03-0.21)$ & NS \\
\hline Uric acid/Cr & $0.93(0.07-2.21)$ & $0.22(0.04-1.56)$ & 0.025 \\
\hline
\end{tabular}

Na: Sodium; K: Potassium; Ca: Calcium; P: Phosphorus; Mg: Magnesium; Cr: Creatinine. 
Significant positive correlations were found between urine KIM-1/Cr, L-FABP/Cr, NAG/Cr and NGAL/Cr ratios in the CD group ( $\mathrm{p}<0.05)$. There were significant negative correlations between serum vitamin B12 level and urine biomarker $/ \mathrm{Cr}$ ratios $(\mathrm{p}<0.05)$. In addition, significant negative correlations were found between values of $\mathrm{Hb}$ and Hct and urine biomarkers'ratios ( $\mathrm{p}<0.05)$. Finally, there were significant negative correlations between RBC and ratios of urine L-FABP/Cr and $\mathrm{KIM}-1 / \mathrm{Cr}$ in CD patients (Table 5).

\section{DISCUSSION}

Increased urinary $\mathrm{Na} / \mathrm{Cr}$ and $\mathrm{UA} / \mathrm{Cr}$ in our CD children may be a sign of tubular dysfunction. In chronic renal failure, urinary injury biomarkers were found to be decreased if low hemoglobin levels corrected by the administration of erythropoietin. ${ }^{9}$ Anemia occurring in CD deficiency may lead to chronic hypoxia. Renal tubular cells had a high metabolic activity and oxygen consumption and highly susceptible to hypoxia. $^{10}$

$\mathrm{KIM}-1$, as a transmembrane protein, is upregulated in proximal tubular cells following ischemic or nephrotoxic injury and is expressed in the fibrotic areas of the damaged kidneys. ${ }^{11} \mathrm{We}$ found increased urinary KIM-1 levels in children with $C D$ as a marker of tubulointerstitial changes.

L-FABP is thought to be an endogenous antioxidant that suppresses tubulointerstitial injury and is a biomarker of chronic renal damage and its progression. ${ }^{12}$ Therefore, urinary L-FABP could be a novel biomarker for chronic intrarenal ischemia. Higher urinary L-FABP excretion was found in our $\mathrm{CD}$ patients may be a sign of chronic hypoxemia resulted from $C D$ anemia.

NAG is an abundant lysosomal enzyme existing in the renal tubular cells and released in the urine during proximal tubular injury. ${ }^{13}$ NGAL is a member of the lipocalin family, and has been identified as a sensitive biomarker of renal tubular damage in acute and chronic nephropathy. ${ }^{14}$ Significantly increased urinary NAG and NGAL excretion in our CD patients may be indicative of subclinical injury of renal tubules.

Damage in kidney tubular cells can lead to tubular dysfunction with impaired electrolytes reabsorption. In our study, increased urine excretion of $\mathrm{Na}$ and uric acid were found. Moreover, increased urine kidney injury molecules of our patient suggested kidney damage. Correlation of these four novel biomarkers indicated that these patients may have kidney damage and these markers are valuable.

Although there was no difference in urine protein/Cr ratios between our CD patients and healthy subjects, Wahlstedt-Fröberg et al., reported elevated excretion of protein in their six patients with Gräsbeck-Imerslund syndrome. Non-elevated urine protein of our patients may be related to different etiopathogenesis of our

TABLE 5. Spearman's correlation coefficients between urinary novel biomarkers and other variables in cobalamin deficiency group

\begin{tabular}{|c|c|c|c|c|c|}
\hline & & NGAL/Cr & NAG/Cr & L-FABP/Cr & KIM-1/Cr \\
\hline \multirow[t]{2}{*}{ B12 } & $\mathrm{r}$ & -0.396 & -0.475 & -0.453 & -0.458 \\
\hline & $\mathrm{p}$ & 0.005 & 0.001 & 0.001 & 0.001 \\
\hline \multirow[t]{2}{*}{$\mathrm{Hb}$} & $\mathrm{r}$ & -0.325 & -0.365 & -0.349 & -0.360 \\
\hline & $\mathrm{p}$ & 0.026 & 0.012 & 0.016 & 0.013 \\
\hline \multirow[t]{2}{*}{$\mathrm{RBC}$} & $\mathrm{r}$ & -0.322 & -0.297 & -0.339 & -0.358 \\
\hline & $\mathrm{p}$ & 0.027 & 0.043 & 0.020 & 0.014 \\
\hline \multirow[t]{2}{*}{$\mathrm{MCV}$} & $\mathrm{r}$ & 0.281 & 0.418 & 0.364 & 0.340 \\
\hline & $\mathrm{p}$ & 0.049 & 0.003 & 0.010 & 0.017 \\
\hline \multirow[t]{2}{*}{ NGAL/Cr } & $\mathrm{r}$ & & 0.931 & 0.969 & 0.977 \\
\hline & $\mathrm{p}$ & & $<0.001$ & $<0.001$ & $<0.001$ \\
\hline \multirow[t]{2}{*}{$\mathrm{NAG} / \mathrm{Cr}$} & $\mathrm{r}$ & & & 0.958 & 0.945 \\
\hline & $\mathrm{p}$ & & & $<0.001$ & $<0.001$ \\
\hline \multirow[t]{2}{*}{$\mathrm{L}-\mathrm{FABP} / \mathrm{Cr}$} & $\mathrm{r}$ & & & & 0.984 \\
\hline & $\mathrm{p}$ & & & & $<0.001$ \\
\hline
\end{tabular}

Hb: Hemoglobin; RBC: Red blood cells; MCV: Mean corpuscular volume;NGAL: Neutrophil gelatinase-associated lipocalin; NAG: N-acetyl-b- D -glucosaminidase; L-FABP: Liver-type fatty acid-binding protein. 
patients (dietary $\mathrm{CD}$ ) contrast to selective B12 malabsorption of Gräsbeck-Imerslund syndrome. ${ }^{4}$

Negative correlations between urinary kidney injury molecules and $\mathrm{Hb}$ and vitamin B12 levels in the $\mathrm{CD}$ deficient group, supports the existence of a chronic process that renal injury increases parallel to deepening of $\mathrm{CD}$.

The main limitation is the small sample size of CD group, and the other limitation is the cross-sectional design of the study. We could not measure urinary biomarkers after completion of cobalamin supplementation due to fall down of most patients from follow up.

In conclusion, despite normal levels of commonly used conventional kidney function tests, increased urine kidney injury molecule levels may indicate the existence of subclinical renal damage in patients with vitamin B12 deficiency.

\section{Acknowledgments}

Authors thank to DUBAP (Dicle University Fund of Scientific Research Projects) for scientific and financial support.

\section{REFERENCES}

1. Briani C, Dalla TorreC,Citton V, Manara R, etal.Cobalamin deficiency: clinical picture and radiological findings. Nutrients 2013;5(11):4521-39.

2. Pawlak R, Lester SE, Babatunde T. The prevalence of cobalamin deficiency among vegetarians assessed by serum vitamin B12: a review of literature. Eur J Clin Nutr 2014;68(5):541-8.
3. Whitehead VM. Acquired and inherited disorders of cobalamin and folate in children. Br J Haematol 2006; 134(2):125-36.

4. Wahlstedt-Fröberg V, Pettersson T, Aminoff M, Dugué B, etal. Proteinuria in cubilin-deficient patients with selective vitamin B12 malabsorption. Pediatr Nephrol 2003;18(5): 417-21.

5. Ozcay F, Derbent M, Aldemir D, Turkoglu S, et al. Effect of iron deficiency anemia on renal tubular function in childhood. Pediatr Nephrol 2003;18(3):254-6.

6. Anderson RJ, Barry DW. Clinical and laboratory diagnosis of acute renal failure. Best Pract Res Clin Anaesthesiol 2004; 18(1):1-20.

7. Scott SP, Chen-Edinboro LP, Caulfield LE, Murray-Kolb LE. The impact of anemia on child mortality: an updated review. Nutrients 2014;6(12):5915-32.

8. Schwartz GJ, Work DF. Measurement and estimation of GFR in children and adolescents. Clin J Am Soc Nephrol 2009;4(11):1832-43.

9. Nakamura T, Sugaya T, Kawagoe $Y$, Suzuki T, et al. Effect of erythropoietin on urinary liver-type fatty-acid-binding protein in patients with chronic renal failure and anemia. Am J Nephrol 2006;26(3):276-80.

10. Nangaku M.Chronichypoxia and tubulointerstitial injury: a final common pathway to end-stage renal failure. J Am Soc Nephrol 2006;17(1):17-25.

11. Lim AI, Tang SC, Lai KN, Leung JC. Kidney injury molecule-1: more than just an injury marker of tubular epithelial cells? J Cell Physiol 2013;228(5):917-24.

12. von Eynatten M, Baumann M, Heemann U, Zdunek D, et al. Urinary L-FABP and anaemia: distinct roles of urinary markers in type 2 diabetes. Eur J Clin Invest 2010;40(2): 95-102.

13. Martensson J, Martling CR, Bell M. Novel biomarkers of acute kidney injury and failure: clinical applicability. $\mathrm{Br} J$ Anaesth 2012;109(6):843-50.

14. Devarajan P. Review: neutrophil gelatinase-associated lipocalin: a troponin-like biomarker for humanacutekidney injury. Nephrology (Carlton) 2010;15(4):419-28. 